\title{
Toward one world or many? A comparative analysis of OECD and UNESCO global education policy documents
}

\author{
Victoria Vaccari - Manufacturing Institute, Washington, DC, USA \\ Meg P. Gardinier* - Indiana Institute of Technology, Fort Wayne, USA
}

\begin{abstract}
Education policymaking has gone global. The 2030 Agenda for Sustainable Development aims to galvanize efforts to promote sustainable development, decrease global inequalities, and realize universal quality education. Supporting these efforts, two leading international organizations, UNESCO and the OECD, have set out normative frameworks for their vision of global education. This paper examines the policy discourses of these organizations in light of SDG 4-Education. Specifically, through a comparative analysis of selected terms and underlying concepts in key policy documents, the paper distinguishes between UNESCO's notion of global citizenship and the OECD's framework for global competence. Ultimately, the authors discuss whether the organizations' agendas are aimed at a common global vision, or, alternatively, towards two distinct and divergent conceptualizations of an imagined future.
\end{abstract}

Keywords: UNESCO; OECD; global citizenship; global competence; SDG 4-Education

\section{Introduction}

In the post-2015 global educational landscape, a range of stakeholders are exploring ways to educate the world's children. The 2030 Agenda for Sustainable Development (Agenda 2030), launched in September 2015 at the United Nations headquarters in New York, aims to galvanize new efforts for sustainable growth and development, to decrease global inequalities, and to promote universal attainment of a quality education through the completion of primary and secondary schooling, at a minimum. Seventeen Sustainable Development Goals (SDGs) have been articulated to enable countries to realize the global targets embedded in the broader international Agenda 2030. In the area of education, SDG 4 is the central goal; it is 'to ensure inclusive and equitable quality education and promote lifelong learning opportunities for all' (https://sustainabledevelopment.un.org/sdg4).

According to a recent document published jointly by the Organisation for Economic Co-operation and Development (OECD) and the Asia Society Center for Global Education:

The purpose of the 17 SDGs is to unite the UN countries around a shared agenda focused on reducing poverty and increasing the quality of life in a sustainable way. ... Education is crucial for reaching all of the SDGs.

Educating for global competence can help engage a rising generation 
in managing and even solving the social, political, economic, and environmental challenges outlined in the SDGs by 2030. (Colvin and Edwards, 2018: 11)

Concepts of global competence and global citizenship are central to the SDG agenda, and are thus increasingly embedded in key international and domestic policy documents. Yet the meanings behind these concepts are far from singular and universal. Small but important differences exist in the language of key documents advocating education for global competence and global citizenship education (GCE). While there is a central alignment to the principles of Agenda 2030 and SDG 4, the underlying orientation of different organizations, the language they adopt in key documents, and the implicit priorities they espouse indicate some areas of divergence in terms of their goals for the future. There are far-reaching implications stemming from the discourses promoted in the global policy statements of certain key international organizations. Ultimately, what is at stake is a question of justice: how can education best serve to reduce global inequalities and cultivate well-being for all throughout the world? According to education policy theorists Rizvi and Lingard (2010: 159), 'the discursive terrain within which educational priorities are now set is increasingly informed by a range of neoliberal precepts that have undermined, in various ways, stronger social democratic claims to educational justice.'

In the interest of discerning the collective futures envisioned by global policy actors in the field of education, this article examines and compares the strategic policy discourses of two key international organizations: the United Nations Educational, Scientific and Cultural Organization (UNESCO) and the OECD. Specifically, through a comparative analysis of select terms and underlying concepts that are embedded in this collection of key policy documents, this article aims to distinguish between UNESCO's notion of global citizenship and the OECD's framework for global competence in order to make sense of the implicit principles and priorities that serve as drivers of twentyfirst century international educational development.

After a brief discussion of the research methods, the findings from a twostage coding process are discussed. We then consider the question of whether the agendas of these two leading international agencies are aimed at a common global vision, or, alternatively, towards two distinct and divergent conceptualizations of an imagined future.

\section{Key concepts}

It is important to contextualize how UNESCO and the OECD define global citizenship and global competence education respectively. The natures of these definitions provide meaningful insight into the aims and motivations behind both organizations' policies. First, it is vital to note that the organizations use different terminology for concepts that aim to reach similar goals.

UNESCO's use of 'global citizenship' implies a focus on multiculturalism, activism, and an engaged application of the knowledge, skills and attitudes presented in the curriculum in order to make the world a better place for future generations. Drawing on a foundation of human rights, UNESCO (2017: 4) 'seeks to empower citizens to actively resolve global challenges and contribute to a more peaceful, tolerant, inclusive, and secure world.' UNESCO (2014: 15) defines global citizenship education as embodying 'a concern with the relevance of knowledge, skills and values for the participation of citizens in, and their contribution to, dimensions of societal development which are linked at local and global levels.' Furthermore, global citizenship 
represents a supranational 'sense of belonging to a broader community and common humanity' that 'emphasises political, economic, social and cultural interdependency and interconnectedness between the local, the national, and the global' (UNESCO, 2015b: 14).

However, the OECD's use of 'global competence' has a different connotation in the sense that competence implies a focus on a specific set of skills and abilities that can be applied in order to contribute to social and economic productivity in a global society. The use of 'competence' as distinct from 'citizenship' signifies a shift away from an explicitly normative value orientation concerning issues of human rights and justice. However, like UNESCO's definition of global citizenship, the OECD's construct of global competence also incorporates the three dimensions of knowledge/understanding, skills/abilities and attitudes/values. For example, the OECD (2016a: 1) defines global competence as 'the acquisition of in-depth knowledge and understanding of global and intercultural issues, the ability to learn from and live with people from diverse backgrounds; and the attitudes and values necessary to interact respectfully with others.'

Thus, while a priority is placed on the cognitive dimensions of global competence, including knowledge and skills related to the analysis of global and intercultural issues, the OECD also mentions normative values and attitudes in connection with respect for human dignity and the diverse backgrounds of individuals. Where the organizations differ, however, is in their articulation of the roles and responsibilities that accompany global knowledge, skills and attitudes. While UNESCO emphasizes notions of supranational identity and belonging, the OECD places more emphasis on the economic necessity of global competence. Interestingly, both definitions markedly extend beyond the limitations of traditional conceptions of national economic development and citizenship, and instead locate the individual in the wider social, political and economic context of globalization.

\section{Theoretical perspectives}

In order to analyse the differing policy agendas of UNESCO and the OECD, we draw on various theoretical perspectives, including international institutionalism, world culture theory, global education policy, cosmopolitanism and, most directly, human capital theory and human capability theory. These theoretical frameworks help elucidate the different purposes, outcomes and implications of global citizenship and global competence education, and connect strongly with the global policy aspirations of the two organizations.

Comparative and international education scholars take different views on the work of international organizations in global education policymaking (Mundy et al., 2016; Rizvi and Lingard, 2010; Verger et al., 2018). According to Steiner-Khamsi (2016: 587), 'we are dealing today with the phenomenon of global norm-setting in education. It is not so much the fact that this phenomenon exists, but rather that the processes, mechanisms, and agencies that perpetuate it should be subject to scrutiny.' For Ramirez et al. (2016: 60), 'the national era now co-exists with a post-nationalist global agenda, and national educational policy-making coexists with much global educational policy.'

Through the development of standard indicators for educational performance, encapsulated in assessments such as the Programme for International Student Assessment (PISA), the OECD has emerged at the forefront of what world culture theorists assert is an increasing convergence and standardization of educational policy and institutional development across diverse nation states (Ramirez et al., 
2016; Wiseman and Stevens Taylor, 2017). For the OECD (2016a, 2016b), education can address many of the difficult situations in our world faced by employers and policymakers alike, especially regarding preparing the next generation for a rapidly changing and interconnected globalized world (see also Schleicher and Zoido, 2016).

Since the 2010s, research on the role of the OECD in global governance has proliferated (for example, see Gardinier, 2017; Lingard and Sellar, 2016; Martens and Jackobi, 2010; Morgan and Volante, 2016; Mundy et al., 2016; Niemann and Martens, 2018; Ougaard, 2010; Sellar and Lingard, 2013, 2014; Wiseman and Stevens Taylor, 2017). This literature builds on previous research on globalization, international organizations and education (see, for example, Henry et al., 2001; Kamens and McNeely, 2010; Martens, 2007), as well as earlier discussions of the historical development of educational multilateralism (Mundy, 1998). Mundy (1998: 477) argued that the early post-Second World War period was characterized by 'the promotion of a Keynesian welfare state societal compromise within advanced capitalist countries', which gave rise to organizations such as the OECD and UNESCO. However, 'though the vestiges of this order remain in place, it is clear that the postwar order's domestic and international compromises have been displaced by economic globalization and the emergence of neoliberalism as the guiding paradigm for public policy' (Mundy, 1998: 477).

Within the neo-liberal paradigm, the discourse of human capital has remained central. According to Morgan and Volante (2016), the OECD shifted from a Keynesian policy approach to a neo-liberal economic policy approach in the 1980s. This shift had profound effects at the OECD in terms of education; in particular, the OECD launched the International Indicators and Evaluation of Educational Systems (INES) project in 1988, which paved the way for the development of standardized indicators for educational assessment that are seen today in the OECD Programme for International Student Assessment (Gardinier, 2017; Morgan and Volante, 2016).

These initiatives are largely guided by the OECD's underlying philosophy that, 'economic success crucially relies on human capital - the knowledge, skills, competencies and attributes that allow people to contribute to their personal and social well-being, as well as that of their countries' (Angel Gurria, OECD SecretaryGeneral quoted in Keeley, 2007: 4). Specifically, in the Foreword to Keeley's (2007: 3-4) book, Gurria outlined the following:

Education is the key factor in forming human capital. People with better education tend to enjoy higher incomes - a benefit that is also reflected in improved economic growth. But the impact of human capital goes beyond economics. ... Given its significance for economic and social development, human capital has long been a priority subject for the OECD, which is heavily involved in education; working to develop understandings of how teaching and learning can be improved in the classroom and helping education systems in member countries to learn from each other's successes and failures.

According to Morgan and Volante (2016), this overtly neo-liberal approach to educational development is critiqued and contested by many global education researchers.

Theoretically speaking, the human capital approach posits education as a vehicle for obtaining skills and knowledge to augment a person's income-generating abilities and to increase productivity in the workforce as a whole. Robeyns (2006: 72) maintains that 'human capital theory considers education relevant in so far as education creates skills and helps to acquire knowledge that serves as an investment in the productivity of 
the human being as an economic production factor, that is, as a worker.' The emphasis on skills and knowledge applies to two of the three main components routinely cited as elements of global citizenship and global competence education.

Although often a straightforward and instrumental way to qualify the purpose of education, human capital theory falls short in explaining the third element involved in global citizenship or global competence education: attitudes and values. Robeyns (2006) considers the theory to be narrowly economistic and instrumental because it does not explain the attitude of a person to studying something without personal economic benefit. In this regard, human capital theory focuses on skills and knowledge as means to an end (global citizenship or competence as a way to improve the workforce), rather than an end in itself(developing unique and globally conscious individuals), while leaving no room for attention to the cultivation of broader attitudes and values. Nussbaum (2009) also critiques the human capital approach because of its tendency to marginalize or downplay the significance of groups of people that would not traditionally contribute to raising a nation's GNP, such as women in developing countries.

Accordingly, Nussbaum (2009) espouses human capability theory, which is predicated on a critique of the dominant human capital paradigm, and places issues of social justice at the centre of its conceptualization. For Nussbaum (2003b: 33), Amartya Sen's capability approach has always focused on issues of economic empowerment and well-being; she argues that 'growth is a bad indicator of life quality because it fails to tell us how deprived people are doing', especially women, 'who are often unable to enjoy the fruits of a nation's general prosperity.' The human capability approach thus focuses on how education enhances both individual and societal well-being, especially through policy implementation that benefits all elements of society. 'Against the dominant emphasis on economic growth as an indicator of a nation's quality of life', Nussbaum (2003b: 33) notes, 'Sen has insisted on the importance of capabilities, what people are actually able to do and to be.' Human capability theory advocates for the creation of opportunities that allow people to reach their full human potential through policies that empower and preserve human dignity. Nussbaum argues that human capability, not functioning, should be the political aim of education, for it encompasses a broader conceptualization of social justice for all (see also Ragland, 2015).

The human capability approach incorporates all three elements of global citizenship and competence education, as knowledge is a means of flourishing, skills contribute to social cohesion and the betterment of society, and attitudes and values set the stage for the active application of positive change through education. Human capability theory views education as a means to develop the full human being through a variety of disciplines and methods that affect a person's emotional, personal and intellectual development (Nussbaum, 2003a, 2006). In developing the full human being, there is also an emphasis on developing that person's values and attitudes in order to spur on societal growth and positive change. This aligns well with the definition of citizenship education for the betterment of humanity or society, but does not clearly outline a path to this positive change or the pedagogy involved in developing human capabilities.

As the lead organization spearheading the realization of the Sustainable Development Goals (SDGs) and the 2030 Education Agenda, UNESCO has articulated a broad platform for educational development that involves widespread participation at the country level. In recent documents such as the Incheon Declaration and Framework for Action (UNESCO, 2015a) and Rethinking Education: Towards a global common good (UNESCO, 2015b), UNESCO has positioned educational development as a means towards greater social justice and equality in the service of a common 
humanity. These documents invoke both theoretical perspectives of human capability theory and, to some degree, human capital theory.

Thus, both UNESCO and the OECD set out clear normative frameworks for a vision of education around the world, recognizing the need for development in the face of globalization and the need for greater human well-being. However, while the articulation of these norms may seem convergent in some ways, there are nonetheless several areas of policy divergence between the two organizations that are valuable to consider. We therefore compare the normative policy orientations of the two organizations with a view toward the broader influence and impact that their divergence, and areas of convergence, have on the future that is envisioned for education in diverse contexts.

\section{Research questions and methodology}

Based on the theoretical perspectives discussed above, and the preliminary review of definitions of global citizenship and global competence, we investigate the following research questions:

1. How do UNESCO and the OECD conceptualize the purposes of education in a global context?

2. How are these purposes represented in the discourse of policy documents and agendas, particularly those related to global citizenship and global competence?

3. What might be the implications of these policy discourses on educational systems in diverse national contexts?

To investigate these questions, we analysed core texts on global citizenship and global competence released in recent years by both organizations, and coded them as a pilot for a larger body of work. Frameworks for global citizenship education and global competence continue to be developed, particularly in the case of the OECD, as in 2018 it implemented the first global competence assessment. With this ongoing development, further study of these concepts and frameworks will be necessary. However, for this preliminary study, our research was limited to core texts published at the time of submission. From the OECD, the document Global Competency for an Inclusive World (2016a) was used, which delineates the OECD's vision for global competence as an educational priority in preparation for its measurement in the 2018 PISA examination. From UNESCO, the document Global Citizenship Education: Preparing learners for the challenges of the 21st century (2014) was reviewed and analysed. As described below, two rounds of analytic coding were used for each document.

In developing the coding schema for this study, we chose to focus first on what the outcomes of global citizenship or global competence would be, and second on how those outcomes interacted with key concepts from our theoretical framework, namely those presented in human capital and human capability theories. The codes were identified after reviewing the documents for all possible outcomes of the two approaches, and were ultimately selected from keywords in the texts. While it is possible that alternative codes could have been selected, and may be selected for a future analysis of these organizations' policy documents, for this preliminary study, the selection of codes was guided by the actual language presented in the texts, and then clustered according to 'meta-themes' that represented a fairly standard breakdown of educational objectives: knowledge, skills, attitudes and values.

In the first round of thematic coding, we focused on the 'what' of global citizenship or global competence education. This analysis focused on identifying 
mentions of the concepts' 'measurable' components, which were determined to be 'knowledge and understanding', 'skills and behaviours' and 'attitudes and values'. These categories corresponded with much of the existing literature on teaching global citizenship or competence, and were therefore also used in both UNESCO's and OECD's policy documents as important components of the discipline. While knowledge, understanding, skills, attitudes and values are not the only possible outcomes of education, both organizations cited their importance throughout the core texts, which narrows their approaches in prescriptiveness, and also what can be coded in terms of educational outcomes for the purpose of this research.

In the second round of coding, we focused on the 'why' of global citizenship or global competence education. In this secondary analysis, three thematic clusters, or meta-themes that corresponded with key concepts drawn from the human capital and/or human capability approaches were identified; these three meta-themes were employment, human dignity and human rights. Drawing on existing literature on various approaches to education, which compared and contrasted rights, capabilities and human capital (see Robeyns, 2006), sub-categories for this cluster were then created from a number of associated words and phrases that further corresponded to, and elaborated upon, the three meta-themes. Table 1 delineates examples of words and phrases used in this two-tiered thematic coding process.

Table 1: Cluster 1 and 2 codes

\begin{tabular}{lll}
\hline Cluster & $\begin{array}{l}\text { Components/ } \\
\text { meta-themes }\end{array}$ & Examples of words/phrases used for coding \\
\hline 1 & $\begin{array}{l}\text { Knowledge and } \\
\text { understanding }\end{array}$ & $\begin{array}{l}\text { Analysis, judgement, identification, 'learn about global } \\
\text { developments of significant', reflection, 'familiarity with } \\
\text { the most important issues', 'examine the roots and } \\
\text { causes of events', 'consider the connections' }\end{array}$ \\
Skills and behaviours & $\begin{array}{l}\text { Intercultural communication, 'resolve persistent } \\
\text { challenges', take action, critical thinking, challenging bias } \\
\text { and stereotypes, social skills such as empathy, flexibility, } \\
\text { conflict resolution }\end{array}$ \\
& $\begin{array}{l}\text { Respect, social cohesion, universality, global solidarity, } \\
\text { advocacy, sensitivity to other cultures, openness, global- } \\
\text { mindedness, responsibility }\end{array}$ \\
& Workforce, career, employer, economic potential \\
& Happiness, fulfilment, well-being, sense of belonging \\
Employment & Human rights, peace, equality, justice, tolerance, \\
Rights & individual rights, children's rights \\
\hline
\end{tabular}

Next, after coding the documents in two rounds, the number of extractions from each document was calculated in order to assess the relative weight placed on the various terms, and to explore whether any themes emerged based on the number of mentions of the codes by each organization.

While this approach to coding made it possible to delineate areas of convergence and divergence in the OECD's and UNESCO's approaches, a different set of codes may have provided different results. As the research is ultimately centred on the outcomes of these two educational policies as indications of normative frameworks of the organizations, the outcomes of global competence and global citizenship education became the focus of our research methodology. 
In sum, through this multi-tiered thematic coding process, we endeavoured to identify the key terms and concepts embedded in the documents, to examine relationships between these codes, and to interpret the relative weight allocated to the various themes and meta-themes in connection with the strategic agendas of the OECD's and UNESCO's current policies towards global competence and global citizenship education respectively. In keeping with the research questions, we also sought to investigate how both UNESCO and the OECD conceptualized these global approaches to education, how the discourses used in their respective policy documents reflected these conceptualizations and, ultimately, what the implications are of these orientations for the organizations' members and constituents.

\section{Results}

After coding the documents and calculating the extractions from each document, specific patterns emerged for both UNESCO and the OECD in terms of their priorities in the promotion of global citizenship or global competence education, as well as within their normative orientations related to determining the 'what' and the 'why' of their global education approaches. Table 2 presents the two clusters used to analyse the documents, the components and meta-themes coded in each cluster, key terms and phrases used to determine coding and, finally, the number of extractions from each organization's document.

Table 2: Thematic coding results

\begin{tabular}{|c|c|c|c|c|}
\hline Cluster & $\begin{array}{l}\text { Components/ } \\
\text { meta-themes }\end{array}$ & $\begin{array}{l}\text { Examples of words/phrases used } \\
\text { for coding }\end{array}$ & $\begin{array}{l}\text { OECD } \\
\text { extractions }\end{array}$ & $\begin{array}{l}\text { UNESCO } \\
\text { extractions }\end{array}$ \\
\hline \multirow[t]{3}{*}{1} & $\begin{array}{l}\text { Knowledge } \\
\text { and } \\
\text { understanding }\end{array}$ & $\begin{array}{l}\text { Analysis, judgement, identification, } \\
\text { 'learn about global developments of } \\
\text { significant', reflection, 'familiarity with } \\
\text { the most important issues', 'examine } \\
\text { the roots and causes of events', } \\
\text { 'consider the connections' }\end{array}$ & 30 & 18 \\
\hline & $\begin{array}{l}\text { Skills and } \\
\text { behaviour }\end{array}$ & $\begin{array}{l}\text { Intercultural communication, 'resolve } \\
\text { persistent challenges', take action, } \\
\text { critical thinking, challenging bias } \\
\text { and stereotypes, social skills such as } \\
\text { empathy, flexibility, conflict resolution }\end{array}$ & 37 & 25 \\
\hline & $\begin{array}{l}\text { Attitudes and } \\
\text { values }\end{array}$ & $\begin{array}{l}\text { Respect, social cohesion, universality, } \\
\text { global solidarity, advocacy, sensitivity } \\
\text { to other cultures, openness, global- } \\
\text { mindedness, responsibility }\end{array}$ & 30 & 32 \\
\hline Cluster & $\begin{array}{l}\text { Components/ } \\
\text { meta-themes }\end{array}$ & $\begin{array}{l}\text { Examples of words/phrases used } \\
\text { for coding }\end{array}$ & $\begin{array}{l}\text { OECD } \\
\text { extractions }\end{array}$ & $\begin{array}{l}\text { UNESCO } \\
\text { extractions }\end{array}$ \\
\hline \multirow[t]{3}{*}{2} & Employment & $\begin{array}{l}\text { Workforce, career, employer, economic } \\
\text { potential }\end{array}$ & 9 & 3 \\
\hline & Dignity & $\begin{array}{l}\text { Happiness, fulfilment, well-being, sense } \\
\text { of belonging }\end{array}$ & 6 & 8 \\
\hline & Rights & $\begin{array}{l}\text { Human rights, peace, equality, justice, } \\
\text { tolerance, individual rights, children's } \\
\text { rights }\end{array}$ & 2 & 11 \\
\hline
\end{tabular}


Taken individually, the OECD and UNESCO policy documents demonstrated some areas of convergence and some areas of divergence in terms of their use of the key concepts (see also Akkari and Lauwerier, 2015). In the sections below, the results for each organization are presented sequentially.

\section{OECD}

In the first round of coding the OECD document (2016a), several trends became increasingly clear. First, the prevalent use of global 'competence' rather than global 'citizenship' indicated a strong association with skills and abilities. The term 'competence' also referred to a measurable end point of the educational process, signalling the linear development of skills, from novice to mastery. This approach aligned primarily with the conceptual framework of human capital theory, in which skills and knowledge are valued in order to advance economic growth and productivity.

It is not surprising that the OECD policy document focused strongly on the measurable components of global competence due to its ongoing development of the PISA instrument. According to Sellar and Lingard (2014: 932), 'The spatiotemporal expansion of PISA and the creation of other programmes such as PIAAC and PISA-based Tests for Schools are also helping to create a global infrastructure for human capital assessment.' The focus on quantifying students' knowledge, skills and attitudes very much informed how the OECD approached these dimensions of global competence (OECD, 2018). While all three components play a role in the development of global competence, certain components may be easier to assess, measure and align within the OECD's underlying affinity with human capital theory.

Related to this analysis, the first cluster of coding indicated that the OECD (2016a) document showed a preference towards 'skills and behaviour', with 37 mentions, while 'knowledge and understanding' and 'attitudes and values' were tied for mentions at 30 each. Many of the mentions of skills were applicable to the workplace, such as intercultural communication, critical thinking and speaking a foreign language. These all contribute to education as an investment (Robeyns, 2006), and align with the themes behind human capital theory, since this vision of global competence would develop 'hard' skills that contribute to workforce development in the global knowledge economy. Although mentioned less frequently, the OECD also cited 'soft' skills such as 'flexibility' and 'empathy', which can both be learnt in school and ultimately may be measured on the 2018 PISA global competence assessment through the qualitative student questionnaire. An emphasis on skills and behaviour, however, does not necessarily imply that these skills would be employed for any form of social change action. Therefore, the second-tier cluster of coding adds more context to how the OECD views skills as a component of global competence.

The emphasis on 'knowledge and understanding' in the OECD report focused more on understanding global issues than on understanding other cultures. This knowledge, in turn, is seen to contribute to students' ability to think critically and analyse complex situations and scenarios. Knowledge and understanding, however, are relatively easier to measure through the cognitive component of the PISA examination, and therefore are the least troublesome of the three components to assess through such an instrument. Students' attitudes towards, and understanding of, other cultures, while still measurable, are not necessarily as clear cut and straightforward as a measurable concept that would contribute to global competence.

Lastly, the emphasis on 'attitudes and values' in the document centred on the attitudes of 'openness towards people from other cultures, respect for cultural otherness, global-mindedness [and] responsibility', as well as 'valuing human dignity' 
and 'valuing cultural diversity' (OECD, 2016a: 14, 17). The OECD (2016a: 14) considers these attitudes and values 'foundational to the development of the knowledge and skills needed for Global Competence.' However, while the attitudes and values for global competence seem necessary in order to develop the knowledge and skills described, attitudes and values are the hardest to measure, and therefore are more implicit in the normative orientation of the OECD's educational policies concerning global competence than skills, the strongest focus, and knowledge, the easiest to assess and measure. Indeed, in the diagram mapping the assessment of these aspects of global competence in the 2018 framework (OECD, 2018: 22), knowledge and cognitive skills are shown to be assessed in both the cognitive test and the student questionnaire, while social skills and attitudes are only shown to be assessed in the qualitative student questionnaire. In this diagram, the category of 'Values' is shown to be 'beyond the scope of the PISA 2018 assessment' (OECD, 2018: 22). Figure 1 indicates the percentages of mentions of codes in the cluster 1 analysis for the OECD document.

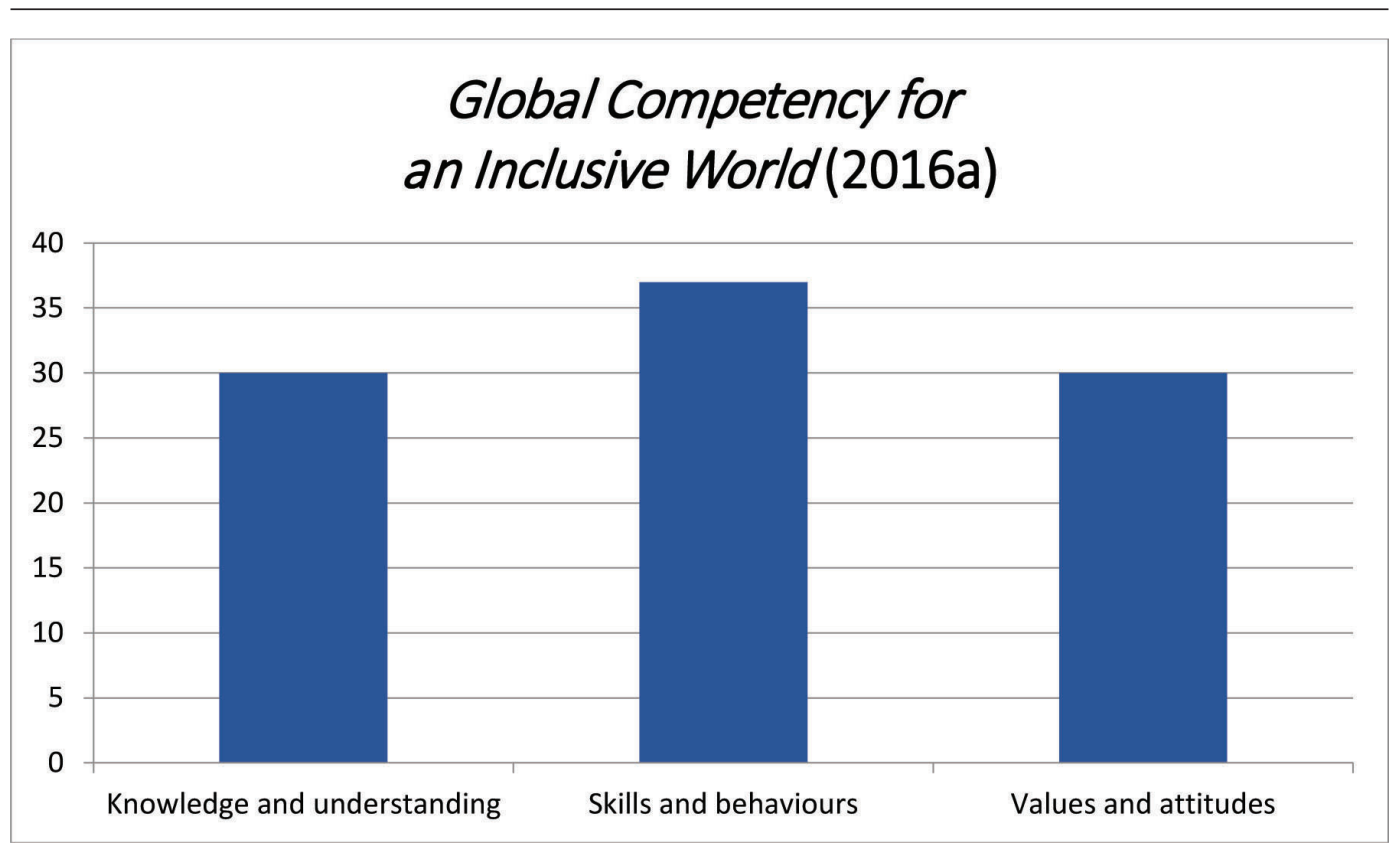

Figure 1: OECD (2016a) Cluster 1 codes

In the second-tier cluster of coding (see Figure 2), the OECD established a greater inclination towards the theme of 'employment' with nine mentions, over 'dignity' (six) and 'rights' (two). This coincides with the findings of the Cluster 1 codes, as many of the mentions of skills were directed towards their use and usefulness in the workplace, further demonstrating an alignment with human capital theory. The document (OECD, 2016a) seemed to favour as a whole the inclusion of globally competent learners in the workplace, over their participation in the greater global sphere, with little mention of discourses surrounding human rights, dignity or justice. This emphasis on employment demonstrates the OECD's orientation in terms of the educational aims of its global competence assessment: measure what is taught and learnt as it aligns with preparation for the global workforce. Given the OECD's wider policy goals as presented in the literature, this analysis provides further evidence that the OECD is positioning itself to set a normative agenda for local or national governments to follow in the interest of educating the next generation for the global twenty-first-century workforce. 
This top-down approach to education policymaking may have wider implications for what should be taught and measured in the future.

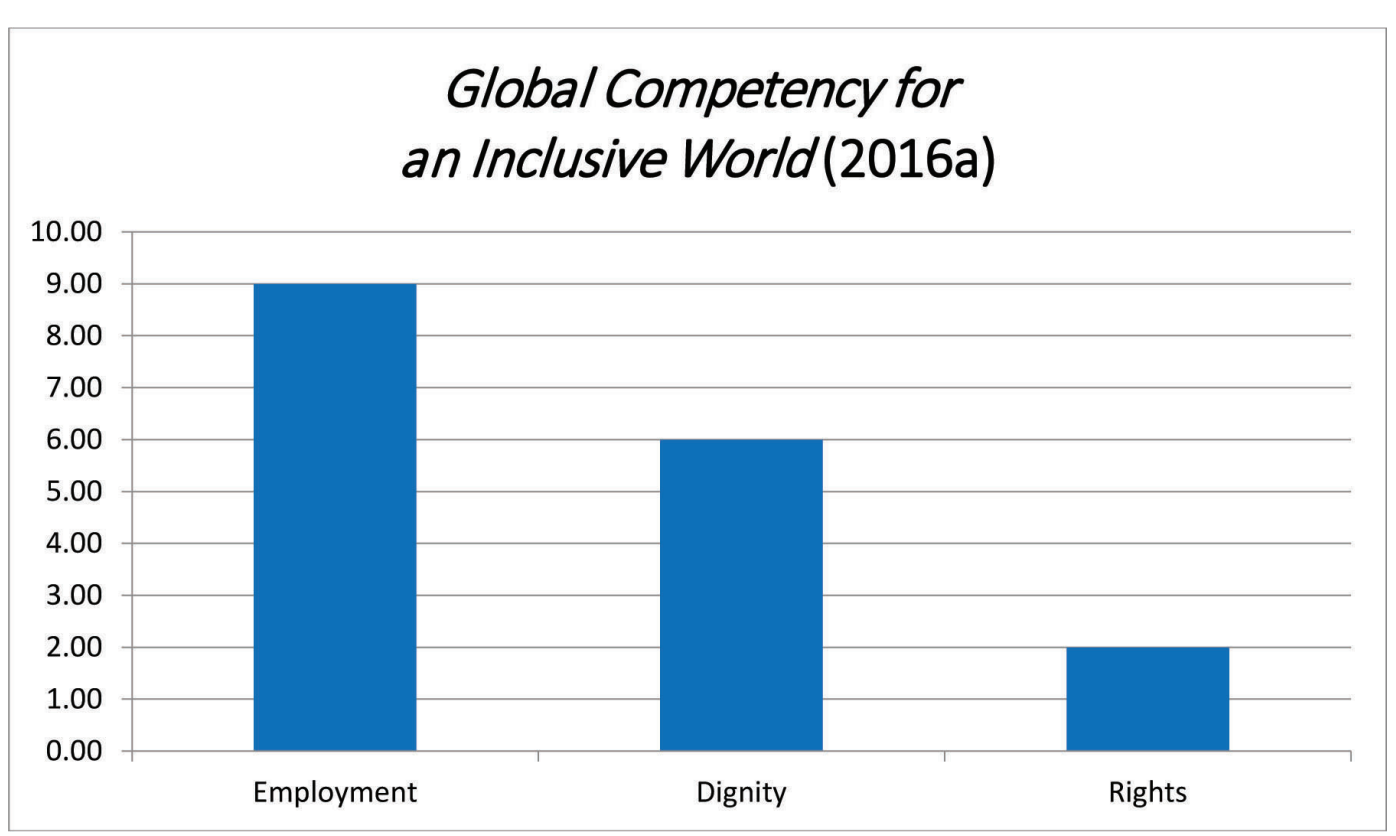

Figure 2: OECD (2016a) Cluster 2 codes

\section{UNESCO}

The first round of coding analysis of the UNESCO (2014) report Global Citizenship Education: Preparing learners for the challenges of the 21st century presented UNESCO's focus as an organization in terms of its values regarding global citizenship education. As previously stated, the use of 'citizenship' (rather than 'competence') in UNESCO documents points to a strong association with civic values and a priority to highlight relevant issues connected to one's status as a citizen and holder of rights. Due to the focus on educating the whole individual in order to provide the learner with the capacity to flourish, and the more humanistic focus on 'being and doing', the UNESCO framework aligns more closely with human capability theory than with the human capital model of education.

Although UNESCO is not as prescriptive in its approach to global citizenship education as the OECD is in its approach to global competence, the organization does advocate elements of global citizenship education that can be tailored to fit into a local curriculum. This approach, which advocates that the local context should influence the global approach, may make creating global citizens a more nuanced and democratic goal; however, it may imply that there will be far less consistency in what comprises the specific knowledge, skills, attitudes and values associated with global citizenship education, which could prove to be a weakness. The potential conflict between universality and particularity becomes much more nuanced within the narrative of UNESCO's global citizenship education policies, and therefore there are no set prescriptions on the conceptual content of what a nation should teach in terms of global citizenship. In practice, this too aligns with the tenets of human capability theory, as learners should be equipped with what it takes to live a dignified life in the world they inhabit, which may not be that of a globalized workforce. 
The first cluster of coding demonstrated an alignment with UNESCO's definitions of global citizenship through the prioritization of discussing 'attitudes and values', with 32 mentions, whereas 'skills and behaviour' had 25 mentions, and 'knowledge and understanding' had 18 mentions (see Figure 3). Many of the mentions of attitudes and values dealt with a focus on intercultural understanding and identity, and the promotion of universality while respecting singularity (UNESCO, 2014). Intercultural understanding coincides with the principles of human capability theory, since the learning outcomes of values and attitudes surrounding intercultural understanding translate to a respect for human dignity and individual agency.

In contrast to the OECD, UNESCO's focus on skills was greatly tailored to enacting social change as a global citizen, and not necessarily focused on hard skills that are measurable and transferrable to employment in the global knowledge economy. The document repeatedly referred to cognitive skills such as critical thinking, social skills such as conflict resolution, and behavioural skills such as collaborative action, as skills necessary within global citizenship education. All of these skills can be directly applied towards social change, and are discussed in that context within the document.

The third area within the UNESCO report - 'knowledge and understanding' focused more on the understanding of rights and justice, as well as understanding multiple perspectives in comparison to understanding global issues. A grasp of global issues was still a priority for UNESCO's global citizenship framework; however, this knowledge is embedded in a larger focus on an understanding of rights and justice. This orientation towards knowledge and understanding adds a greater sense of empowerment for the learner, especially when aligned with a human capability perspective. In general, knowledge and understanding in UNESCO's paradigm constituted more of a 'consciousness in and around real-life issues', as opposed to a measurable component for a global benchmark (UNESCO, 2014: 21).

\section{Global Citizenship Education: Preparing learners for the challenges of the 21st century (2014)}

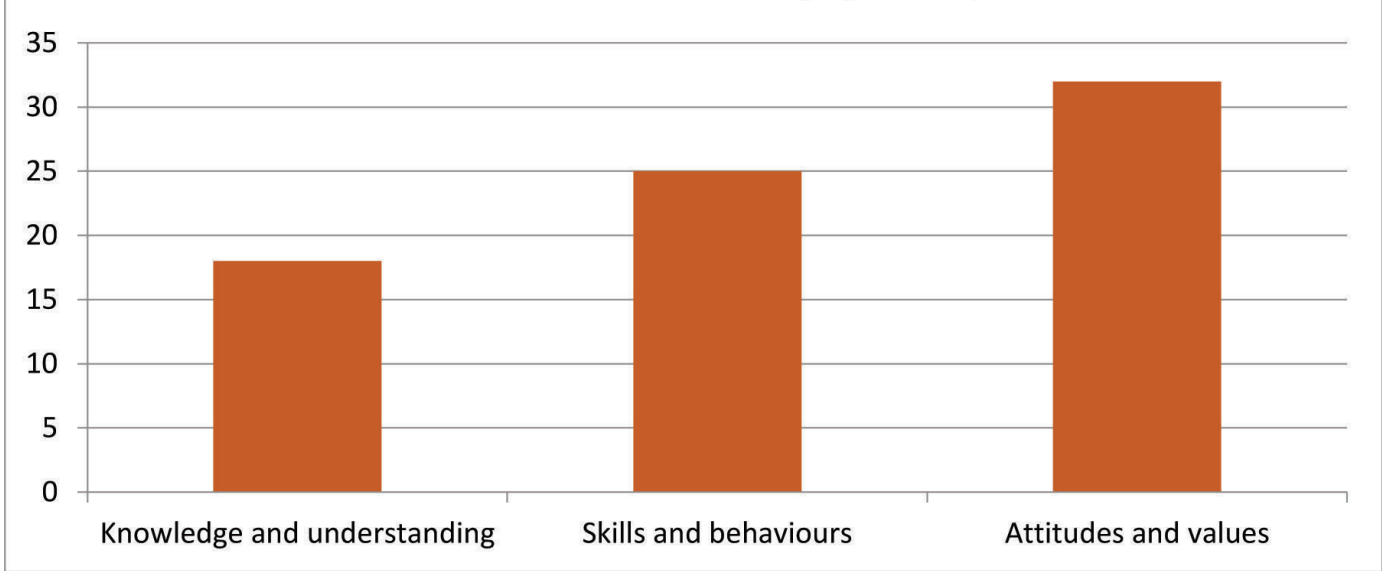

Figure 3: UNESCO (2014) Cluster 1 codes

In the second cluster of coding, the UNESCO report showed a preference towards 'rights', with 11 mentions, whereas 'dignity' had 8 mentions and employment had 3 mentions (see Figure 4). These data coincide well with the coded mentions of 'values 
and attitudes' as well as 'knowledge and understanding' within the first coding cluster, since both focused on universal values and human rights. The document seemed to value human dignity in conjunction with rights, with repeated reference to the value of '[belonging] to a common humanity', while reinforcing this sense of belonging with the rights it entails (UNESCO, 2014: 17). This shared sense of belonging is also representative of UNESCO's focus on attitudes and values, which are more beneficial in embracing a common humanity than employment-orientated skills or knowledge.

\section{Global Citizenship Education: Preparing learners for the challenges of the 21st century (2014)}

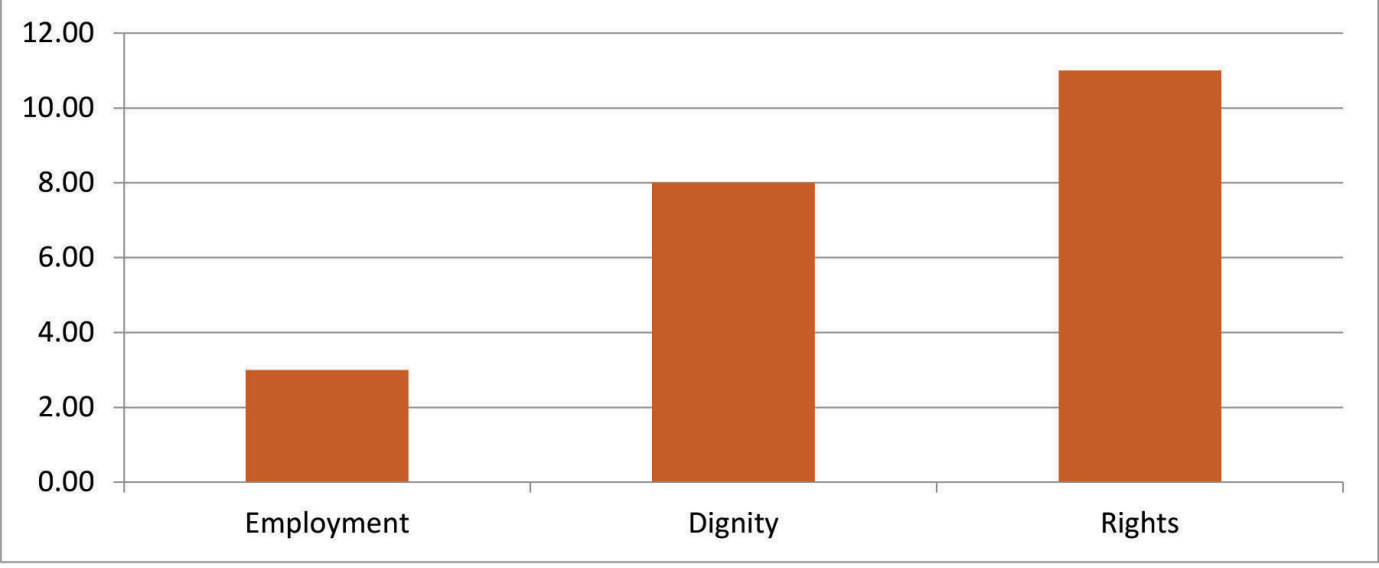

Figure 4: UNESCO (2014) Cluster 2 codes

\section{Comparative analysis}

Both UNESCO and the OECD are in some areas pursuing similar practices, but with different theoretical orientations and frameworks. Furthermore, both organizations are actively envisioning the world beyond today, through to 2030. However, the underlying approaches they take, and the meanings attributed to the various components of their frameworks, diverge. As demonstrated in Figures 5 and 6, although both stress knowledge, skills and attitudes, they place significantly different emphases on each area. For the OECD, the skills of global competence education are central, whereas for UNESCO, the values and attitudes of global citizenship play a much stronger role.

According to this comparative analysis, we can understand the priority purposes of education in UNESCO and OECD strategies respectively as follows:

1. Education for a common humanity: intercultural understanding; empathy; social cohesion; education as a site of membership, inclusion, and belonging; education as a human right and a global common good.

2. Education for a global knowledge economy: skills and dispositions for a global workforce; flexible skills for a mobile workforce; measurable skills for a competitive workforce; national economic growth through educational attainment. 


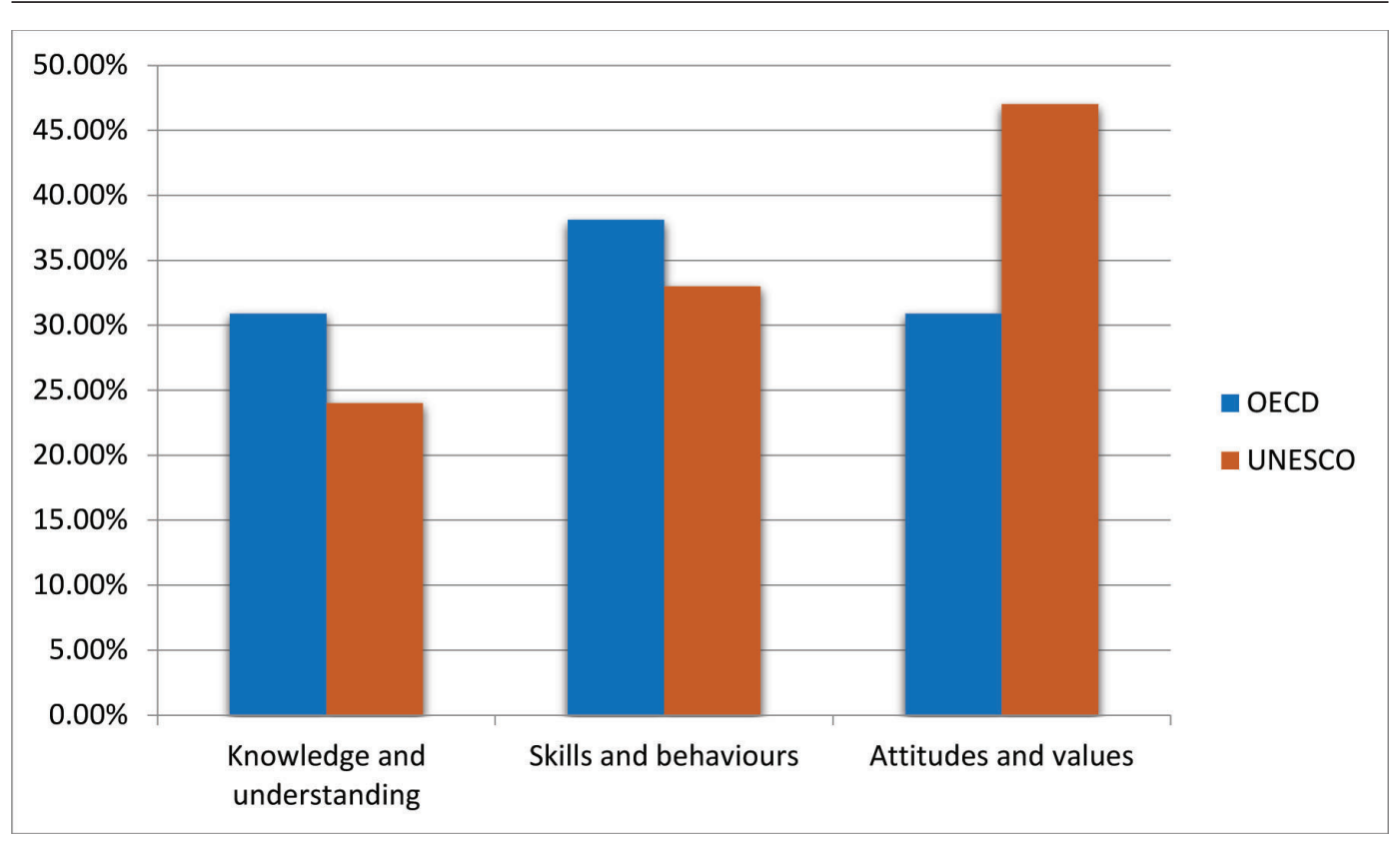

Figure 5: Comparison of OECD and UNESCO Cluster 1 codes

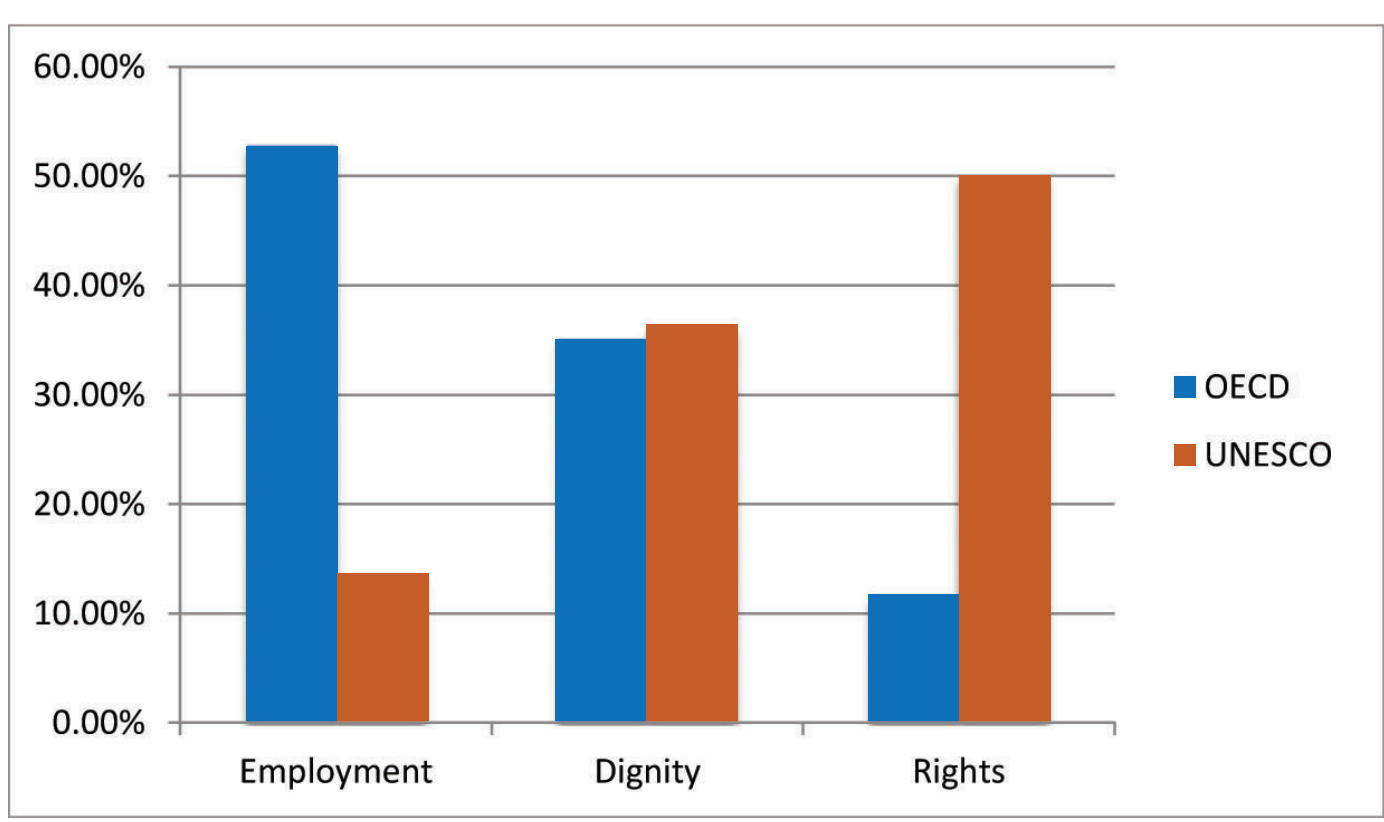

Figure 6: Comparison of OECD and UNESCO Cluster 2 codes

The divergence of these two orientations for the imagined futures has implications for how the next generation will continue shaping our globalized world. On the one hand, the imagined future presented by $\operatorname{UNESCO}(2014,2015 b)$ in 'educating for a global common good' could empower students, especially marginalized populations, to address global inequalities and global issues such as migration or climate change, as well as to create more inclusive societies on local, national and global levels. On the other hand, the future presented by the OECD, in focusing on developing a globally competent and productive workforce, could also bring about social change through economic competition and development. However, the focus on educating for a competitive workforce, rather than educating for a shared common humanity, 
could also potentially propel greater nationalism, deepen inequalities, or perpetuate toxic environmental practices that disproportionately affect poorer communities as countries compete to claim their share of the global economy.

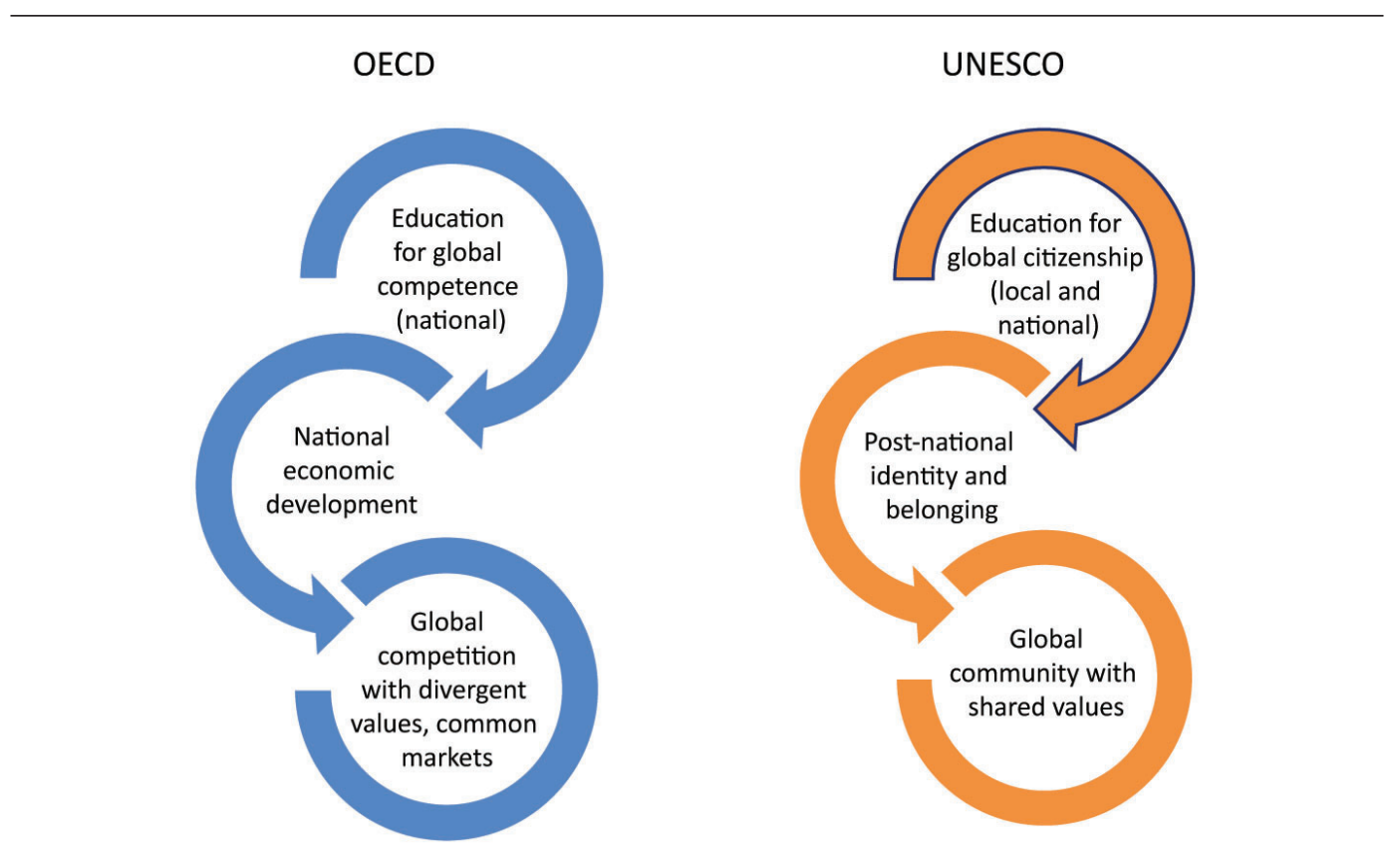

Figure 7: Pathways of policy discourse

In the depictions in Figure 7, two divergent pathways of educational development are presented. In the case of the OECD, education for global competence as a national strategy could foster greater attention to national-level needs and workforce demands, leading governments to promote policies for greater competitive advantage within the global economy. In the case of UNESCO, education for global citizenship could foster educational development for both greater national cohesion amid diversity, as well as greater engagement with the wider world. This focus could lead to policies that promote a sense of post-national identity as global citizens, and a more collective engagement with diverse others throughout the world (O'Byrne, 2003; Ramirez and Meyer, 2012). With an underlying value emphasizing a common humanity, rather than a shared economy, UNESCO's policy documents aim more towards a broader global community based on international normative commitments such as Agenda 2030 and the SDGs. This is not to say that the OECD did not emphasize values at all in their approach to global competence, as tackling inequality for dignity was addressed. However, the focus on addressing inequality was limited, and aligned directly with the model of economic growth through human capital development (Takayama, 2013).

Thus, while the two agendas have areas of convergence, it appears that the divergence would not lead to a similar outcome in the imagined future of 2030. While certain normative elements of the OECD's construct of global competence overlap with UNESCO's concept of global citizenship, the OECD's focus on human capital is unlikely to lead to the same outcomes of greater inclusion and increased opportunities for marginalized populations. A growing number of researchers, however, argue that concepts of global citizenship are problematic and may have limited emancipatory utility, particularly for the Global South. For example, Jooste and Heleta (2017: 47) argue that theories of global citizenship that 'portray the South as the problem, a helpless mass, which cannot survive without the assistance from the "enlightened" 
North, will not make the world a better, more equal place; it will only sow more divisions and animosity'. Instead of advocating abstract theories, they argue, education should 'prepare our students for life in a real and challenging world' by 'developing them into globally competent and socially responsible individuals' that 'possess critical thinking skills, value diversity, and can communicate and collaborate with people from different countries and cultures and work in a complex and constantly changing world' (Jooste and Heleta, 2017: 47).

The emphasis on promoting skills for employment, rather than wider attitudes and norms, may lead to a more equipped workforce, which may also lead to positive social change. However, without a focus on empowerment or a commitment to addressing wider global issues such as climate change or gender injustice, the link between these educational models and the SDGs remains uncertain. In other words, while global competence could very well contribute to social change and a global common good indirectly through creating opportunities for social entrepreneurship and innovation, it is nonetheless far less likely to address inequalities on the level that education for global citizenship could. Alternatively, due to its alignment with the SDGs, global citizenship education could contribute directly to the development of a globally engaged and equipped workforce that possesses the attitudes and values to cooperate with diverse others while concurrently addressing economic inequalities on a macro scale.

To understand the implications and potential effects of these areas of strategic policy divergence, more research is needed to analyse the key mechanisms through which the OECD and UNESCO are actively influencing education policies in diverse education systems around the world, as well as the wider societal effects of this influence.

\section{Discussion}

A central question pertaining to the SDGs is whether governments can commit to pursuing a common global agenda with a multi-pronged approach to sustainability, development and global prosperity. The SDGs are intended to unite the international community by providing 'a shared normative framework that fosters collaboration across countries, mobilizes all stakeholders, and inspires action' (SDSN, 2014: 1). There is little mention in this framework of preparing citizens for participation in the global knowledge economy, yet education is a key driver for reaching many, if not all, of these global goals.

Because UNESCO is the lead UN agency charged with facilitating the realization of the SDG Education 2030 Agenda, with widespread participation at the country level, it is logical that their policy documents reflect the need for educational development as a means towards greater social justice and equality in the service of a common humanity. The OECD has likewise increasingly espoused education for global competence as a means to promote wider social and economic development goals.

However, given our findings that the policy priorities, and the associated normative frameworks, of both organizations diverge in key areas, we must further explore how this will affect efforts to achieve the global goals of Agenda 2030. In particular, we must consider the following: Does it matter if the intended outcomes articulated in the policy platforms of different international actors diverge? What impact would it have if, rather than a 'shared normative framework', the SDGs served to inspire strategies that divided rather than united countries in the pursuit of specific targets and goals at the national level? What if the futures that are imagined and envisioned by different stakeholders who are contributing to policy agendas do not align with the principles of Agenda 2030? Furthermore, what if the global priorities articulated in the SDGs are conceptually incompatible with the underlying theoretical orientation of powerful 
states and global policy actors? To bring these questions out of the abstract realm, we must consider whether the operating assumptions of human capital theory, in its current neo-liberal form, are compatible with the global goals set forth in Agenda 2030. Can international actors devise policies that populate the global workforce with skilled employees while also eliminating extreme poverty and sustaining the planet's ecosystems? Can global education prepare twenty-first-century learners for the global economy, while also cultivating and celebrating a shared humanity with universal dignity and human rights for all?

Adding a theoretical perspective to these questions, Rizvi and Lingard (2010: 16) argue that 'in considering a global analysis of contemporary state activities and relations, we need to take account of history (e.g. colonialism), political aspirations (e.g. post-colonialism) and the state's geopolitical location within a changing world order.' Similarly, Andreotti (2006: 42) cautions that an apolitical framing of global citizenship may serve to reproduce global inequalities and power asymmetries, rather than to level the global playing field. She argues that 'the use of images, figures and slogans emphasized the need to be charitable, compassionate and "active" locally (in order to change institutions), based on a moral obligation to a common humanity, rather than on a political responsibility for the causes of poverty' (Andreotti, 2006: 42). Thus, from this more critical perspective, UNESCO's emphasis on education for a shared humanity does not go far enough in promoting a more just and equitable future for all members of the world community, particularly those in the Global South.

\section{Conclusion}

Ultimately, preparing learners in diverse global locations to address the shared international commitment of Agenda 2030 will require a shift towards a more socially conscious concept of global competence and a more human rights-based and postcolonial approach to global citizenship. In the absence of these reconfigurations, the policies developed by organizations such as the OECD and UNESCO risk perpetuating global inequalities rather than reducing or transforming them.

Moving forward, more work is needed to enrich the OECD's and UNESCO's respective concepts of global competence and global citizenship education, in order to create more cohesive and practical road maps for educators and nations to implement these concepts in the classroom. The normative orientations of these two approaches to global education will have lasting implications for global policy agendas on a greater scale than simply preparing the next generation to function in a globalized economy. The SDGs provide an inclusive and transformative framework in which these organizations have the potential to address a wider range of global issues and institute positive change by directly confronting inequalities and injustice, rather than merely perpetuating existing social and economic structures. While more study on the practical implementation of global citizenship and global competence education is needed, this paper's findings suggest that the normative orientations and related policy prescriptions of the OECD and UNESCO are currently leading educators along two distinctly divergent pathways toward the future in 2030.

\section{Notes on the contributors}

Victoria Vaccari is the Director of Women's Engagement at the Manufacturing Institute, the social impact affiliate of the US-based National Association of Manufacturers (NAM). Prior to this position, Victoria worked with the Immigration Partnership and Coalition (IMPAC) Fund in Miami, and with Shorelight Education as an advisor for the Florida 
International University Global First Year programme, where she developed a global citizenship course co-sponsored by UNESCO. Victoria earned her undergraduate degree in political science from George Washington University, and her master's degree in international and intercultural education from Florida International University.

Meg P. Gardinier is an associate professor of global leadership at the Indiana Institute of Technology. She holds a PhD in education from Cornell University and an EdM in international educational development from Teachers College, Columbia University. Her research focuses on global education policy, peace and human rights education. She has served as a consultant to UNESCO on an education policy review in Albania and to the Open Society Foundation-Albania on a research project exploring the implications of the OECD PISA on education in Albania.

\section{References}

Akkari, A. and Lauwerier, T. (2015) 'The education policies of international organizations: Specific differences and convergences'. Prospects, 45 (1), 141-57.

Andreotti, V. (2006) 'Soft versus critical global citizenship education'. Policy and Practice: A Development Education Review, 3, 40-51.

Colvin, R.L. and Edwards, V. (2018) Teaching for Global Competence in a Rapidly Changing World. New York: Asia Society / OECD.

Gardinier, M.P. (2017) 'Looking back toward the future: Reflecting on the OECD's global educational influence'. In Wiseman, A.W. and Stevens Taylor, C. (eds) The Impact of the OECD on Education Worldwide (International Perspectives on Education and Society 31). Bingley: Emerald Publishing, 247-69.

Henry, M., Lingard, B., Rizvi, F. and Taylor, S. (2001) The OECD, Globalisation and Education Policy. Oxford: Pergamon.

Jooste, N. and Heleta, S. (2017) 'Global citizenship versus globally competent graduates: A critical view from the South'. Journal of Studies in International Education, 21 (1), 39-51.

Kamens, D.H. and McNeely, C.L. (2010) 'Globalization and the growth of international educational testing and national assessment'. Comparative Education Review, 54 (1), 5-25.

Keeley, B. (2007) Human Capital: How what you know shapes your life. Paris: OECD Publishing.

Lingard, B. and Sellar, S. (2016) 'The changing organizational and global significance of the OECD's education work'. In Mundy, K., Green, A., Lingard, B. and Verger, A. (eds) The Handbook of Global Education Policy. Chichester: Wiley Blackwell, 357-73.

Martens, K. (2007) 'How to become an influential actor: The "comparative turn" in OECD education policy'. In Martens, K., Rusconi, A. and Leuze, K. (eds) New Arenas of Education Governance: The impact of international organizations and markets on educational policy making. Basingstoke: Palgrave Macmillan, 40-56.

Martens, K. and Jakobi, A.P. (eds) (2010) Mechanisms of OECD Governance: International incentives for national policy-making? Oxford: Oxford University Press.

Morgan, C. and Volante, L. (2016) 'A review of the Organisation for Economic Cooperation and Development's international education surveys: Governance, human capital discourses, and policy debates'. Policy Futures in Education, 14 (6), 775-92.

Mundy, K. (1998) 'Educational multilateralism and world (dis)order'. Comparative Education Review, $42(4), 448-78$

Mundy, K., Green, A., Lingard, B. and Verger, A. (eds) (2016) The Handbook of Global Education Policy. Chichester: Wiley Blackwell.

Niemann, D. and Martens, K. (2018) 'Soft governance by hard fact? The OECD as a knowledge broker in education policy'. Global Social Policy, 18 (3), 267-83.

Nussbaum, M.C. (2003a) 'Women's education: A global challenge'. Signs: Journal of Women in Culture and Society, 29 (2), 325-55.

Nussbaum, M.C. (2003b) 'Capabilities as fundamental entitlements: Sen and social justice'. Feminist Economics, 9 (2-3), 33-59.

Nussbaum, M.C. (2006) 'Education and democratic citizenship: Capabilities and quality education'. Journal of Human Development, 7 (3), 385-95.

Nussbaum, M.C. (2009) 'Creating capabilities: The human development approach and its implementation'. Hypatia, 24 (3), 211-15. 
O'Byrne, D.J. (2003) The Dimensions of Global Citizenship: Political identity beyond the nationstate. London: Frank Cass.

OECD (Organisation for Economic Co-operation and Development) (2016a) Global Competency for an Inclusive World. Paris: Organisation for Economic Co-operation and Development. Online. http://tinyurl.com/yy5ye63j (accessed 14 March 2019).

OECD (Organisation for Economic Co-operation and Development) (2016b) Strategic Orientations of the Secretary-General for 2016 and Beyond: Meeting of the OECD Council at Ministerial Level, Paris, 1-2 June 2016. Paris: Organisation for Economic Co-operation and Development. Online. http://tinyurl.com/y556mh8z (accessed 14 March 2019).

OECD (Organisation for Economic Co-operation and Development) (2018) Preparing Our Youth for an Inclusive and Sustainable World: The OECD PISA global competence framework. Paris: Organisation for Economic Co-operation and Development. Online. http://tinyurl.com/y9qws7nu (accessed 14 March 2019).

Ougaard, M. (2010) 'The OECD's global role: Agenda-setting and policy diffusion'. In Martens, K. and Jakobi, A.P. (eds) Mechanisms of OECD Governance: International incentives for national policy-making? Oxford: Oxford University Press, 26-49.

Ragland, D. (2015) 'Betty Reardon's philosophy of peace education and the centrality of justice'. Journal of Peace Education, 12 (1), 37-55.

Ramirez, F.O. and Meyer, J.W. (2012) 'Toward post-national societies and global citizenship'. Multicultural Education Review, 4 (1), 1-28.

Ramirez, F.O., Meyer, J.W. and Lerch, J. (2016) 'World society and the globalization of educational policy'. In Mundy, K., Green, A., Lingard, B. and Verger, A. (eds) The Handbook of Global Education Policy. Chichester: Wiley Blackwell, 43-63.

Rizvi, F. and Lingard, B. (2010) Globalizing Education Policy. London: Routledge.

Robeyns, I. (2006) 'Three models of education: Rights, capabilities and human capital'. Theory and Research in Education, 4 (1), 69-84.

Schleicher, A. and Zoido, P. (2016) 'The policies that shaped PISA, and the policies that PISA shaped'. In Mundy, K., Green, A., Lingard, B. and Verger, A. (eds) The Handbook of Global Education Policy. Chichester: Wiley Blackwell, 374-84.

SDSN (Sustainable Development Solutions Network) (2014) Principles for Framing Sustainable Development Goals, Targets, and Indicators (Issue Brief). Paris: Sustainable Development Solutions Network. Online. http://tinyurl.com/y3j4qwbz (accessed 14 March 2019).

Sellar, S. and Lingard, B. (2013) 'The OECD and global governance in education'. Journal of Education Policy, 28 (5), 710-25.

Sellar, S. and Lingard, B. (2014) 'The OECD and the expansion of PISA: New global modes of governance in education'. British Educational Research Journal, 40 (6), 917-36.

Steiner-Khamsi, G. (2016) 'Global indicators and local problem recognition: An exploration into the statistical eradication of teacher shortage in the post-socialist region'. In Mundy, K., Green, A., Lingard, B. and Verger, A. (eds) The Handbook of Global Education Policy. Chichester: Wiley Blackwell, 573-89.

Takayama, K. (2013) 'OECD, "key competencies" and the new challenges of educational inequality'. Journal of Curriculum Studies, 45 (1), 67-80.

UNESCO (United Nations Educational, Scientific and Cultural Organization) (2014) Global Citizenship Education: Preparing learners for the challenges of the 21st century. Paris: United Nations Educational, Scientific and Cultural Organization. Online. http://tinyurl.com/y6c5t2vs (accessed 14 March 2019).

UNESCO (United Nations Educational, Scientific and Cultural Organization) (2015a) Education 2030 Incheon Declaration and Framework for Action: Towards inclusive and equitable quality education and lifelong learning for all. Paris: UNESCO Publishing. Online. https://unesdoc. unesco.org/ark:/48223/pf0000245656 (accessed 14 March 2019).

UNESCO (United Nations Educational, Scientific and Cultural Organization) (2015b) Rethinking Education: Towards a global common good? Paris: UNESCO Publishing. Online. http://tinyurl. com/y2a2fipm5 (accessed 14 March 2019).

UNESCO (United Nations Educational, Scientific and Cultural Organization) (2017) Education Transforms Lives. Paris: United Nations Educational, Scientific and Cultural Organization. Online. http://tinyurl.com/y43teyka (accessed 14 March 2019).

Verger, A., Novelli, M. and Altinyelken, H.K. (eds) (2018) Global Education Policy and International Development: New agendas, issues and policies. 2nd ed. London: Bloomsbury Academic.

Wiseman, A.W. and Stevens Taylor, C. (eds) (2017) The Impact of the OECD on Education Worldwide (International Perspectives on Education and Society 31). Bingley: Emerald Publishing. 